\title{
CUIDADO E CONFORTO DURANTE O TRABALHO DE PARTO E PARTO: NA BUSCA PELA OPINIÃO DAS MULHERES ${ }^{1}$ \\ CARE AND COMFORT DURING LABOUR AND DELIVERY: SEARCHING FOR WOMEN'S OPINIONS \\ CUIDADO Y CONSUELO DURANTE EL TRABAJO DE PARTO Y PARTO: EN LA BUSCA POR LA OPINIÓN DE LAS MUJERES
}

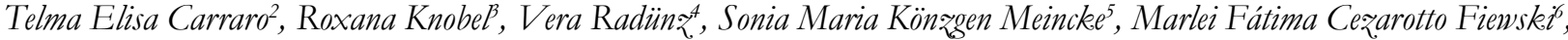 \\ Ariane Thaise Frello, Marisa da Silva Martins ${ }^{8}$, Caroline Vasconcellos Lopes ${ }^{9}$, Andressa Berton ${ }^{10}$
}

${ }^{1}$ Projeto de pesquisa "Opinião das mulheres puérperas sobre os métodos utilizados para seu cuidado e conforto no trabalho de parto e parto" financiado pelo Conselho Nacional de Desenvolvimento Cientifico e Tecnológico (CNPq), tendo como coordenadora a Professora Doutora Telma Elisa Carraro.

${ }^{2}$ Enfermeira. Pós-Doutora em Enfermagem. Docente do Departamento e da Pós-Graduação em Enfermagem (PEN) da Universidade Federal de Santa Catarina (UFSC). Líder do Grupo de Pesquisa Cuidando e Confortando (C\&C) no PEN/UFSC. Santa Catarina, Brasil.

${ }^{3}$ Médica obstetra. Doutora em Medicina. Pós-Doutora em Enfermagem. Docente do Departamento de Tocoginecologia da UFSC. Membro do Grupo de Pesquisa C\&C no PEN/ UFSC. Santa Catarina, Brasil.

${ }^{4}$ Enfermeira. Pós-Doutora em Enfermagem. Docente do Departamento e do PEN/UFSC. Vice-líder do Grupo de Pesquisa C\&C no PEN/UFSC. Santa Catarina, Brasil.

${ }^{5}$ Enfermeira. Mestre em Assistência de Enfermagem. Doutoranda do PEN/UFSC. Docente do Departamento de Enfermagem da Faculdade de Enfermagem e Obstetrícia da Universidade Federal de Pelotas (UFPEL). Membro do Grupo de Pesquisa C\&C no PEN/UFSC. Bolsista Coordenação de Acompanhamento de Pessoal de Nível Superior (CAPES)/Programa de Qualificação Institucional (PQI). Rio Grande do Sul, Brasil.

${ }^{6}$ Enfermeira. Mestre em Engenharia da Produção. Docente do Colegiado do Curso de Enfermagem da Universidade Estadual do Oeste do Paraná (UNIOESTE). Membro do Grupo de Pesquisa C\&C no PEN/UFSC. Paraná, Brasil.

${ }^{7}$ Graduanda em Enfermagem na UFSC. Bolsista do Programa Institucional de Bolsas de Iniciação Científica (PIBIC). Membro do Grupo de Pesquisa C\&C no PEN/UFSC. Santa Catarina, Brasil.

${ }^{8}$ Graduanda em Enfermagem na UFSC. Membro do Grupo de Pesquisa C\&C no PEN//UFSC. Santa Catarina, Brasil.

${ }^{9}$ Graduanda em Enfermagem na UFPEL. Rio Grande do Sul, Brasil.

${ }^{10} \mathrm{Graduanda}$ em Enfermagem na UNIOESTE. Paraná, Brasil.

PALAVRAS-CHAVE: Avaliação em saúde. Satisfação dos consumidores. Assistência ao paciente. Primeira fase do trabalho de parto. Segunda fase do trabalho de parto.
RESUMO: A obstetrícia moderna considera o parto um evento médico-cirúrgico e adota um modelo de assistência tecnicista. Esperava-se que os avanços tecnológicos auxiliassem o trabalho dos cuidadores, proporcionando condições e tempo para ser e estar junto à parturiente. No entanto, esse avanço tecnológico e científico mostra uma enorme fragilidade no que se refere ao cuidado. Realizou-se uma pesquisa quali-quantitativa, descritiva prospectiva, que avaliou a opinião das mulheres puérperas sobre os métodos utilizados para seu cuidado e conforto durante o trabalho de parto e parto. Este trabalho é um recorte dos dados qualitativos, focando os sentimentos das mulheres puérperas durante esta vivência. Com os resultados, pretende-se contribuir na adaptação dos métodos de cuidado e conforto, proporcionando um trabalho de parto humanizado, reforçando na parturiente a confiança em si mesma e na equipe, facilitando e incentivando o parto normal e o exercício saudável da sexualidade, bem como a prevenção das mortes maternas.
KEYWORDS: Health evaluation. Consumer satisfaction. Patient care. First labor stage. Second labor stage.
ABSTRACT: Modern Obstetrics considers delivery a medical-surgical event, adopting a technical assistance model. It is expected that through technological advances caregivers would be assisted in their work, allowing them to have time and conditions to spend with the laboring mother. However, this technological and scientific advancement shows an uncertainty regarding care. A qualitative-quantitative prospective and descriptive research study was completed, evaluating opinions of women about care methods used to care and comfort them during labour and delivery. This paper shows qualitative data focusing on the feelings of puerperal women during the experience. The results are expected to contribute to an adoption of care and comfort methods, leading to a more humanized delivery, which enhances the woman's self confidence, and her confidence in the professional team. It will also facilitate and encourage natural delivery and the healthy performance of sexuality, as well as the prevention of maternal deaths.
Endereço: Telma Elisa Carraro R. das Acácias, 121, B1. B3, Ap. 50 88.040-560 - Carvoeira, Florianópolis, SC, Brasil. E-mail: telmacarraro@nfr.ufsc.br
Artigo original: Pesquisa

Recebido em: 30/10/2006 Aprovação final: 18/04/2007 
PALABRAS CLAVE: Evaluación en salud. Satisfacción de los consumidores. Atención al paciente. Primer periodo del trabajo de parto. Segundo periodo del trabajo de parto.
RESUMEN: La obstetricia moderna considera el parto un evento médico-quirúrgico y adopta un modelo de asistencia técnica. Se esperaba que estos avances tecnológicos ayudasen el trabajo de los cuidadores, proporcionando condiciones y tiempo para ser y estar junto al ser humano. Sin embargo, el adelanto tecnológico y científico muestra una enorme fragilidad en relación al cuidado. En el presente estudio, se realizó una investigación cualitativa y cuantitativa, descriptiva prospectiva, que evaluó la opinión de las mujeres puérperas sobre los métodos utilizados para su cuidado y consuelo durante el trabajo de parto y en el parto. Este trabajo es un recorte de los datos cualitativos, enfocando los sentimientos de las mujeres puérperas durante esta vivencia. Con los resultados obtenidos deseamos contribuir en la adaptación de los métodos de cuidado y consuelo, proporcionando un trabajo de parto humanizado, desencadenando en la parturienta su confianza en sí misma y en el equipo, facilitando e incentivando el parto normal, el ejercicio saludable de su sexualidad y también la prevención de la muerte materna.

\section{INTRODUÇÃO}

O processo do nascimento é intrínseco ao viver da humanidade, conforme a cultura e o meio em que a mulher-mãe está inserida, razão pela qual seu trabalho de parto e parto podem, ser vivenciados com maior ou menor intensidade, refletindo direta ou indiretamente em seu processo de viver.

A tendência mundial de avanço tecnológico e científico mostra uma enorme fragilidade no que se refere ao cuidado e conforto, principalmente, ao que diz respeito a esta vivência. $O$ que se esperava era que os avanços tecnológicos auxiliassem no trabalho dos profissionais, contribuindo assim para que os cuidadores tivessem mais condições para ser e estar junto ao ser humano por eles cuidado. ${ }^{1}$

Essa tendência pode ser claramente observada na obstetrícia moderna, a qual tem priorizado pela hospitalização da parturiente no momento da efetivação do parto considerando-o como um evento médico-cirúrgico, resultando em um modelo tecnicista, que prima pela racionalidade e pela carência de princípios humanísticos. ${ }^{2-3}$ Desse modelo, acrescenta-se à percepção cultural de que toda a dor é um sintoma de doença e deve ser suprimida, resultando a crença de que a dor no parto é dispensável e sem valor e deve ser tratada com equipamentos e tecnologias apropriados. ${ }^{2}$

Ao considerar o cuidado e o conforto durante o trabalho de parto, não se deve simplificar e considerar apenas o alívio da dor. Cuidar é olhar, enxergando; ouvir, escutando; observar, percebendo; sentir, empatizando com o outro, estando disponível para fazer com ou para o outro. ${ }^{4} \mathrm{~A}$ condição essencial para que ocorra o conforto é proporcionar um ambiente favorável, ou seja, um ambiente em que a pessoa seja cuidada e sinta que está sendo cuidada, pois lhe foi oferecido/ofertado afeto, calor, atenção e amor e estes favorecerão o alívio, a segurança e o bem-estar. ${ }^{5}$ Segundo os con- ceitos citados anteriormente, pode-se perceber que o cuidado e o conforto estão intimamente ligados e são primordiais durante o trabalho de parto e parto.

O alívio total da dor não necessariamente implica em uma experiência de parto mais satisfatória. ${ }^{6}$ No entanto, se a mulher sentir-se cuidada e confortada esta experiência poderá ser menos traumática, até porque, atualmente, as mulheres não temem apenas a dor no parto, elas sentem medo em relação aos cuidados que receberão, uma vez que as experiências estão repletas de atendimento impessoal e distante. ${ }^{3}$

Ouro fator a ser considerado neste contexto é que, quanto mais cresce o nível de complexidade das ações, por exigir atuação interdisciplinar e intersetorial articulada, torna-se mais difícil realização destas ações pela insuficiência em número e capacitação de pessoal. ${ }^{7}$ Esse fato realça a necessidade da adoção de medidas de cuidado e conforto adequadas para evitar que a violência se instale durante o processo de nascimento.

Dessa maneira, podemos afirmar que diversos itens são importantes para o cuidado e conforto durante o trabalho de parto e parto, os quais são difíceis de mensurar e, talvez por isso, sejam pouco estudados. Esta pesquisa se apóia em autor que propõe a condução do cuidado de modo a potencializar o poder vital, ou seja, o poder interior da mulher-mãe. ${ }^{8}$ Para isso, indica como componentes do cuidado: a atenção ao estado emocional da parturiente; as relações interpessoais (entre a mulher e sua família/acompanhantes, entre a mulher e a equipe, entre as mulheres companheiras de hospitalização); o conforto e bem-estar em amplo sentido e as condições do ambiente (por exemplo, o respeito à intimidade e privacidade, um ambiente tranqüilo e confortável).

Os recursos para o cuidado e conforto no trabalho de parto e parto devem ser considerados 
como um procedimento no qual se devem pesar riscos e benefícios e também o desejo da mulherparturiente. ${ }^{6}$ Muitos são os métodos disponíveis para o conforto e alívio da dor nesta vivência, tanto farmacológicos, como não-farmacológicos. Outro fator que comprovadamente ajuda a mulher neste momento, inclusive com redução dos níveis de dor, é a presença de acompanhante durante o trabalho de parto, tanto do acompanhante escolhido pela mulher (marido, mãe, amiga) quanto de acompanhante especificamente treinada para o acompanhamento do trabalho de parto, chamada Doula. A presença da Doula foi relacionada com menor dor, menor necessidade de analgesia, menor taxa de partos operatórios e maior satisfação com o parto. ${ }^{9-10}$ Estas presenças podem ser consideradas confortantes e cuidativas.

Outro fator relevante são as orientações à mulher-parturiente para que não permaneça deitada, para deambular, sentar-se na "bola de parto" ou no "cavalinho", pois estas atividades ajudam no conforto. Banhos de banheira parecem ser bastante eficazes no alívio da dor, mas não há estudos sobre banhos de chuveiro, embora a prática clínica indique que estes podem proporcionar alívio. Outros métodos são utilizados para o conforto como: massagens, hipnose, aromaterapia, música e audio-analgesia. Assim como, a acupuntura e técnicas relacionadas, por exemplo, à estimulação elétrica trans-cutânea são alternativas para o alívio da dor no trabalho de parto. ${ }^{9-11}$

Existem muitas pesquisas sendo realizadas com o propósito de avaliar a eficácia dos métodos utilizados. A maioria dos autores se limita a acompanhar o nível de dor e/ou a necessidade de métodos analgésicos adicionais àquele que se está avaliando. Mas existem poucos estudos avaliando a opinião das mulheres sobre o cuidado e o conforto recebidos durante o parto. ${ }^{6}$ Acreditamos que, através do conhecimento da opinião das mulheres-puérperas a respeito de suas vivências, será possível adequar os métodos de cuidado e conforto e proporcionar um trabalho de parto humanizado, desencadeando na mulher-parturiente confiança em si mesma e na equipe, fatos que facilitam e incentivam o parto normal, bem como o exercício saudável de sua sexualidade. Cuidar e confortar é mais que aliviar a dor, pois "ao considerar o cuidado e o conforto durante o trabalho de parto, não se deve levar em conta apenas o alívio da dor". ${ }^{11: 11}$ Cuidar e confortar é também considerar a mulher como ser integral e singular, respeitando inclusive sua sexualidade e evitando expô-la a situações violentas, sejam estas anônimas ou explícitas.

\section{METODOLOGIA}

A pesquisa da qual se originou este texto buscou conhecer a opinião de mulheres puérperas sobre os métodos utilizados para seu cuidado e conforto durante seu trabalho de parto e parto.

É um estudo quali-quantitativo, descritivo-prospectivo, multicêntrico, envolvendo três instituições da Região Sul do Brasil: Universidade Federal de Santa Catarina (UFSC), Departamento de Enfermagem (NFR), Programa de Pós-Graduação em Enfermagem (PEN), Grupo de Pesquisa Cuidando \& Confortando (C\&C) e Hospital Universitário Dr. Polydoro Ernani de São Thiago (HU) - em Florianópolis, Santa Catarina; Universidade Federal de Pelotas (UFPEL), Faculdade de Enfermagem e Obstetrícia e Hospital Escola (HE) - em Pelotas, Rio Grande do Sul e Universidade Estadual do Oeste do Paraná (UNIOESTE), Colegiado do Curso de Enfermagem e Hospital Universitário (HU) - em Cascavel, Paraná.

Participaram do estudo mulheres puérperas que tiveram seus trabalhos de parto e partos acompanhados nos hospitais participantes da pesquisa, desejaram participar e assinaram o consentimento pós-informação.

A coleta de dados foi realizada através de entrevistas que, posteriormente, foram transcritas e analisadas. Os dados foram identificados por um número seguido da sigla de seu estado de origem, ou seja, SC, RS ou PR - ex. 28SC - assim, o sigilo da fonte das informações está sendo mantido, pois é um compromisso ético assumido.

Em relação aos aspectos éticos, antes do início do estudo, foi obtido o consentimento formal das instituições participantes e aprovação pelo Comitê de Ética da UFSC sob o parecer N 319/2004.

Os dados foram tratados e analisados segundo o referencial escolhido e operacionalizados em três etapas: ${ }^{12}$ ordenação dos dados, classificação dos dados e análise final. É importante registrar que essa é uma apresentação didática do tratamento dos dados, pois este ocorre num processo contínuo e simultâneo, com passos articulados e complementares entre si, visando apreender a realidade tal como se apresenta aos olhos das pesquisadoras, tendo o suporte do referencial teórico. ${ }^{8}$ 


\section{NAS FALAS DAS MULHERES PUÉRPE- RAS: SEUS SENTIMENTOS SOBRE O CUIDADO E CONFORTO}

No presente texto, apresentamos um recorte dos dados qualitativos que emergiram no estudo junto às mulheres puérperas, a respeito de cuidado e conforto durante seus trabalhos de parto e parto, mais especificamente, sobre seus sentimentos durante esta vivência. Para tanto suas falas foram organizadas em três categorias: sentimentos durante o trabalho de parto; sentimentos durante o parto; e sentimentos sobre o cuidado e conforto recebido durante o trabalho de parto e parto.

\section{Sentimentos durante o trabalho de parto}

Ao serem questionadas sobre como se sentiram durante o trabalho de parto, ou seja, desde a internação até o momento do início do parto propriamente dito, as mulheres dividiram-se entre sentir-se bem e sentir-se mal.

As mulheres puérperas nas três instituições do estudo que referiram sentir-se bem justificaram que a presença da equipe contribuiu para este sentimento, conforme podemos ver nos dados: [...] percebi atenção dos profissionais, a bigiene do ambiente. O atendimento em si foi completo (18SC); [...] fui bem acolbida, tratada com respeito e atenção. Desde o momento que internei até o nascimento do bebê não fiquei sozinha. Já cheguei segura, pois tinha ouvido falar do atendimento (21SC); [...] pela segurança. Sempre tendo alguém acompanhando. A enfermeira junto na sala de parto também (19SC); [...] porque o atendimento foi bom, não sofri muito, eu cheguei e já ganhei, eles foram atenciosos, conversaram, para não ter medo, ter paciência (01RS); [...] porque eu tive confiança na profissional que tava me atendendo (08RS); [...] porque aqui eles fizeram de tudo para me ajudar e dor todo mundo sente (23RS); [...] porque as gurias eram bem atenciosas, me explicavam tudo direitinho e foi rápido (28RS); [...] porque veio o médico formado e me ensinou como se fazpara ter o bebê. Depois veio o acadêmico e também me ensinou (28PR).

As puérperas do HU/UFSC enfatizaram ainda que a ausência de dores contribuiu para que se sentissem bem: [...] ainda não tava com dor (04SC); [...] muito bem. Porque não senti dor. Tava apavorada pensando que ia doer muito (17SC); [...] foi muito rápido (03SC).

Por outro lado, houve mulheres que disseram sentir-se mal salientando a dor como causa: $[\ldots]$ por causa das contrações (06SC); [...] dores (11SC); [...] dores muito fortes (13SC); [...] por causa das contrações (23SC); [...] terrível. Com muita dor (24SC); [...] muito mal. Muita dor (25SC); [...] devido à dor, ao soro que incomoda muito. Como era induzido achei que não teria dilatação suficiente, estava com medo de ir para cesárea (03RS); [...] porque tinha muita dor, nem sabia que era tanto assim (11RS); [...] porque as dores foram ficando muito mais fortes, foi pior que todos os outros filhos (14RS); [...] a dor era tanta que eu não sei nem o que eu senti, não sei explicar (24RS); [...] porque eu nunca tinha sentido aquela dor (27RS); [...] porque é uma tortura, dói muito (30-RS); [...] era uma dor que vinha depois parava (01PR); [...] não estava sentindo aquela dor insuportável, mas estava mal. (07PR); [...] a dor era forte e já não tinha mais forças (08PR); [...] a dor era muito forte, faltava ar, vomitei bastante (11PR); [...] porque doeu muito e fiquei três dias com dor (24PR); [...] porque dói muito. Fiquei histérica (26PR); [...] doeu, foi ruim no início, mas foi rápido (22PR).

Algumas puérperas apontaram outras causas por sentirem-se mal: [...] falta de atendimento, pouca atenção. Médica querida, mas o resto foi horrível. Demora no atendimento. Tive que pedir pra fazer o toque (24SC); [...] porque eu vim e fui pra casa e eles não quiseram me internar. Tava com muita dor (28SC); [...] porque me senti mal. Vomitei. Desconforto (15SC); [...] porque não tava muito bem preparada (16SC); [...] porque eu estava com medo do parto (20SC); [...] porque ninguém podia me ajudar. Eu sentia dor e estava preocupada, ansiosa com o parto (25PR).

Quanto à referência sobre sentir-se mais on menos, as causas diferem nos três hospitais do estudo como podemos ver a seguir. Uma das mulheres entrevistadas no HU/UFSC enfatizou sentir-se mais ou menos, apresentando altos e baixos: $[\ldots]$ não tem controle sobre a situação. Não tem volta, a dor passa e fica bem, alguém dá apoio, brinca, mas quando a dor volta, vem tudo de novo (07SC).

No HE/UFPel as mulheres puérperas relataram sentir-se mais ou menos devido ao trabalho de parto demorado e ansiedade com relação ao que poderia acontecer no parto: [...] porque foi bem demorado, senti muita dor, ela (bebê) estava muito alta, custou para descer (05RS); [...] porque as dores eram muito fortes, mas os médicos eram bons (06RS); [...] porque eu estava com pressa, porque eu queria que o nenê nascesse rápido, pois eu estava de castigo aqui desde quarta (12RS); [...] porque eu fiquei apavorada quando eu fiquei sabendo que eu tinha que fazer cesárea (15RS).

E, no HU/UNIOESTE, as mulheres puérperas referiram que o sentir-se sozinha contribuiu para sentir-se mais ou menos e também que não foi tão difícil o processo: [...] não sofri muito, foi rápido, as dores não eram tão fortes (13PR); [...] não foi tão sofrido não (15PR); [...] me senti sozinha. Ninguém vinha me ver. Sentia dor também, por isso mais ou menos (16PR). 
Os sentimentos que emergiram nas falas das mulheres puérperas das três instituições destacam o sentir-se bem em virtude da presença e da atenção que receberam da equipe o que as fortaleceu durante o trabalho de parto. No entanto, houve situações em que a ausência/falta de orientação da equipe desencadeou o sentir-se mal.

Percebe-se que a dor é algo muito forte em nossa cultura e a sensação dolorosa foi um dos elementos mais citados nas falas das mulheres. Este foi um fator que emergiu tanto como sentimento bom quanto ruim, e a sua ausência favoreceu o sentir-se bem no trabalho de parto.

\section{Sentimentos durante o parto}

Quando perguntamos às mulheres puérperas sobre como se sentiram durante o parto e porque se sentiram assim, elas referiram sentir-se mal, mais ou menos e/ou bem.

Quanto a se sentir mal, as respondentes registraram a dor como causa: [...] por causa das dores (06SC); [...] muita dor (12SC); [...] pela dor (16 SC); [...] porque a dor ficou mais forte ainda, quase não suportei (2006RS); [...] devido à dor, se não fosse a ajuda deles acho que não iria agüentar (11RS); [...] porque doeu né (22PR); [...] pois senti muita dor (24PR).

No entanto algumas mulheres puérperas acrescentaram outros desconfortos: [... p porque deu câimbra nas duas pernas (03SC); [...] o bebê nasceu com quase 5 quilos, não tinha espaço, o bebê teve que ser puxado, não havia dilatação. Por isso o bebê apresentou luxação na clavicula (04RS); [...] porque ele era muito grande, os outros eu fiz. uma força só e saiam, mas este en tive que fazer umas quatro forças (14RS); [...] porque é ruim, sofri um monte. Principalmente quando está saindo (17PR).

Outras mulheres puérperas relataram que se sentiram mais ou menos por diferentes motivos: [...] pela dor (04SC); [...] alivio. Passou as dores (09SC); [...] bastante cólica (25SC); [...] tava com o pé atrás. Medo, preocupação porque ele não chorou (26SC); [...] pois não via a hora de nascer; mas na hora até que foi um pouco mais rápido do que en imaginava (02RS); [...] pois já estava mais perto de passar, então era melhor. Nessa hora estava mais tranqüila, pois já faltava pouco (03RS); [...] porque não foi tão ruim, mas também não foi bom porque a contração já tinha diminuido (29RS); [... mais ou menos. Não sei (29PR).

O fato de que a maioria das mulheres puérperas sentiu-se bem chama a atenção, apesar de no trabalho de parto terem se sentido mal. Em suas falas surge fortemente o alívio como sensação de bem- estar: [...] aliviada depois de tanto tempo com dor (OSSC); [...] alivio, sensação agradável da saída (11SC); [...] alivio. $A$ dor some na hora (13SC); [...] porque me senti aliviada (17SC); [...] bem, porque eu já estava com falta de ar e muita dor, estava esgotada. Quando saiu foi um alivio (21SC); [...] foi um alivio na minha barriga, fiquei contente, porque o bebê era macho, as outras são todas meninas (01RS); [...] me senti aliviada por não ter mais contração. Felicidade em ser mãe (24RS); [...] pelo alivio de estar tudo bem com ela (25RS); [...] porque de tanta dor que eu senti antes, na bora que ela nasceu foi muito bom, um alivio (27RS); [... porque aliviou a dor do momento (01PR); [... é um alivio, passa tudo, a dor acaba (09PR); [...] fiz só duas forças e o neném nasceu. Foi muito rápido (28PR).

Surge também a felicidade nas falas das entrevistadas: [...] porque foi um alivio e felicidade, na hora que o bebê veio foi bem rápido. Foi um alivio tão grande, parece que sain uma tonelada de mim (20SC); [...] vi que estava tudo bem com o bebê. Terminou a dor e estava feliz. por ser mãe (18SC); [...] felicidade. É uma emoção única (19SC); [...] me senti contente (14SC); [...] porque eu senti muita confiança na profissional, foi uma sensação maravilhosa (08RS); [... porque deu tudo bem, o bebê nasceu bem com saúde, perfeitinho (12RS); [...] porque deu tudo certo, ela nasceu perfeita. Porque a minha pressão alta não complicou (13RS); [...] bem, porque ele nasceu (21RS); [...] porque vê a carinha do bebê, se sente bem, vê que valeu a pena (02PR); [...] é muito bonito, fiquei feliz (05PR); [...] ah, uma sensação maravilhosa, eu estava esperando por isso (07PR); [...] a felicidade é tanta, não tem explicação (15PR); [...] na hora da saída me senti bem porque a dor estava passando/ diminuindo. (16PR); [...] fiquei feliz por ver o rosto dele, foi emocionante (20PR); [...] pude ver que a minha filha era mesmo saudável, fiquei feliz. (21PR).

No que tange aos sentimentos que as mulheres vivenciaram durante o parto, constatamos que elas se sentiram mal devido à dor, que se destaca mais uma vez, mas também houve relatos de outros desconfortos, tais como: câimbras, tamanho do bebê e sofrimento no período expulsivo. Entretanto o sentimento que mais aflorou ao sentirem-se bem foi o alívio em ganhar e conhecer o bebê e não ter mais a dor. Outro sentimento que as mulheres relataram e merece destaque é a felicidade com o nascimento do bebê e a concretude de vê-lo perfeito.

\section{Sentimentos sobre o cuidado e conforto rece- bido durante o trabalho de parto e parto}

As mulheres puérperas foram questionadas como se sentiram com relação à forma como foram cuidadas e confortadas durante o trabalho de parto e parto, e porque se sentiram assim. 
Destacou-se aqui a atenção da equipe com as parturientes: [...] atendimento muito bom. Atenção da equipe (03SC); [...] teve bastante suporte, atenção no trabalho de parto (07SC); [...] atenção, humanidade. Tratamento dez (11SC); [...] pessoal bem preparado, enfermeiro, médicos. Eles dão toda atenção pra gente (16SC); [...] fui bem atendida, bem legais e atenciosos (17SC); [...] as pessoas foram muito boas comigo, muito atenciosos (20SC); [...] porque apesar do parto ter sido dificil, a equipe me tratou bem. Foram atenciosos, preocupados com men bem-estar (04RS); [...] porque eu tive atenção e bons cuidados. Me atenderam bem, foram atenciosos (17RS); [...] recebi atenção dos médicos e enfermeiros. Atenção profissional (26RS); [...] porque eles eram muito gente fina, me trataram muito bem, me deram muita atenção (27RS); [...] porque as pessoas que estavam no momento foram bem atenciosas, passaram tranqüilidade (01PR); [...] a equipe era muito atenciosa, querida (03PR); [...] eles são atenciosos, não faltou nada (07PR); [...] as moças que cuidam são muito queridas, têm paciência, são atenciosas (11PR).

Algumas mulheres puérperas salientaram o tratamento/atendimento: [...] fui bem tratada pelos funcionários (04SC); [...] o atendimento que eles deram. Estavam sempre perto (06SC); [...] trataram bem, me ajudaram quando precisava (09SC); [...] ninguém foi grosso. Todos me atenderam bem (14SC); [...] me trataram muito bem (28SC); [...] me trataram super bem, falaram que era para mim ter calma, que era bem ligeiro e que já tava na hora (01RS); [...] porque todas às vezes que eu precisava deles, eles estavam ali comigo, e eram bem atenciosos tanto os médicos como os enfermeiros (05RS); [...] porque fui muito bem tratada, eles foram atenciosos, tiveram paciência porque eu fiz. muito fiasco (07RS); [...] me cuidaram até de mais, porque o que en fir foi demais, en beliscava o médico na hora de ganbar e ele me tratava bem (19RS); [...] fui tratada bem. Apesar de pedir que as enfermeiras ficassem comigo no quarto o tempo todo e elas não ficarem. Entendo que elas não podiam (26PR).

Outras mulheres puérperas ainda se referiram à alegria, segurança e conforto: [...] ficaram o tempo todo comigo perguntando se eu estava bem (05 SC); [...] muita alegria e preocupação dos profissionais. Não me senti sożinha (18SC); [...] porque en estava segura, sempre tinha alguém comigo, me confortando, perguntando se eu estava bem. Foi ótimo (21SC); [...] porque a equipe sempre vinha me olhar, sempre que eu chamava alguém vinha, também conversaram muito comigo na hora do parto (03RS); [...] porque me atenderam muito bem, estavam toda hora me perguntando se eu estava me sentindo bem, como eu estava (15RS); [...] porque foram muito carinhosos, tanto comigo quanto com bebê, eles entram aqui já rindo, brincando (22RS); [...] porque eles sempre estavam na minha volta, tentando me acalmar (23RS).

No HU/UNIOESTE surge a terminologia "cuidado" na fala das mulheres puérperas: [...] elas cuidaram muito bem, são carinhosas (04PR); [...] cuidaram muito bem, não posso reclamar (08PR); [...] eles conversam, cuidam muito bem (09PR); [...] não faltou nada, me cuidaram muito bem (10PR).

Algumas poucas mulheres puérperas referiram sentir-se mal: [...] pela médica muito bem. Na hora do parto, muitos estagiários olhando por isso me senti muito mal. Estava pedindo pra eles sairem e ninguém fez nada (24SC); [...] dor horrivel (10SC); [...] pelo fato de ficar muito tempo sozinha, com dor, senti uma falta de paciência por parte da equipe (12PR).

Algumas mulheres puérperas referiram sentirse mais ou menos, e por motivos variados: $[. .$.$] nem$ sempre eles vinham quando eu chamava, não gostei (14PR); [... porque a anestesia não pegou direito e eu senti ela (a médica) cortando (18PR); [...] quando eu cheguei no hospital eu reclamava de dor, e as enfermeiras reclamavam, não gostavam. Mas o médico foi bem atencioso (20PR); [...] a gente não sabe o que está acontecendo, sai liquido e tudo e a gente fica preocupada (25PR); [...] porque eles não me deram muita atenção (24RS).

Durante o trabalho de parto e parto os sentimentos das mulheres puérperas sobre o cuidado e conforto recebidos se configuraram na atenção que tiveram da equipe, no tratamento e atendimento, além da alegria, segurança, cuidado e conforto que os profissionais dispensaram neste período. Por outro lado, houve mulheres que se sentiram mal devido à presença de muitos estagiários e pela falta de paciência dos profissionais.

Assim, considerando que os relatos remetem aos momentos vivenciados no trabalho de parto e parto, podemos inferir que, apesar da dor durante as contrações, na grande maioria, as mulheres sentiram-se seguras e cuidadas pela equipe. A atenção, o conforto, a alegria, a paciência e a presença da equipe foram características fundamentais que potencializaram o poder vital das mulheres. Remetem ainda àquelas situações em que estes sentimentos não estiveram presentes, oscilando entre o sentirse bem e sentir-se mal, até porque a vivência do nascimento de um filho é um evento que gera ambigüidade, caracterizando-se em um momento de vários significados e temores. ${ }^{8}$

\section{ANÁliSE E REFLEXÃo SOBRE A TE- MÁTICA}

Conhecer a opinião das mulheres puérperas sobre suas vivências e o cuidado e conforto recebidos durante seus trabalhos de parto e partos, a nosso ver, podem apontar novas maneiras de cuidado durante este momento ímpar em suas vidas, contribuindo, inclusive, para a prevenção das mortes maternas. 
Os dados aqui apresentados, apesar de terem sido coletados na mesma pesquisa, com o mesmo instrumento, e em hospitais-escola brasileiros, quais sejam HU/UFSC (SC), HE/UFPEL (RS) e HU/UNIOESTE (PR), registram três realidades diferentes. Estas realidades se refletem nos dados e demonstram diferenças tanto nas formas de as mulheres puérperas perceberem o cuidado e o conforto recebido quanto, nas formas de os cuidadores prestarem o cuidado.

A dor surge muito fortemente como causa de mal-estar nos três hospitais, no entanto, algumas mulheres relativizam e afirmam que as dores não foram muito fortes. A presença constante da dor no sentimento das mulheres tanto no trabalho de parto como no parto demonstra o quanto ela é presente em nosso sistema de saúde no que diz respeito ao atendimento ao parto, refletindo ainda sua valorização em nossa cultura. Ao avaliar a satisfação das mulheres, no que se refere ao parto, poucos autores citam a dor ou seu controle nas contrações e período expulsivo como variável importante. ${ }^{13}$

Vale ressaltar que os dados revelam que, assim que o parto acontece, o sentimento que flui é de alívio, de alegria e felicidade, principalmente pela dor ter sido superada e por ter seu filho em seus braços.

Ainda no sentido de mal-estar, as mulheres puérperas salientam a pouca atenção, a falta de paciência e de privacidade, e também a limitação no que se refere à preocupação e ansiedade, enfatizando que estas ninguém poderia ajudar a resolver. Outras respondentes ainda registraram desconfortos variados.

Estas falas vão ao encontro dos achados de outra pesquisa, ${ }^{8}$ realizada em maternidades, a qual demonstra que ao presenciar o cuidado às mulheres percebe-se que o seu conforto e bem-estar não eram priorizados, e que não se notou o entendimento por parte desses profissionais quanto à necessidade de elas receberem um cuidado no pré-parto e parto que lhes proporcionasse saúde, incluindo o conforto e bem-estar durante o seu processo de parturição.

Os dados aqui apresentados apontam, ainda, que esta realidade persiste nos dias atuais, configurando momentos em que a mulher se expõe à vontade da equipe, à violência, encontra barreiras para o exercício de sua cidadania e ainda é tratada como ser assexuado apesar de estar no pleno exercício de sua sexualidade.

A exposição desses fatos demonstra a influência de fatores micro e macroestruturais, que se complementam e potencializam, mostrando que a violência é resultado de uma interação de fatores individuais, incluindo os aspectos biológicos e psicológicos, bem como econômicos, políticos, culturais e sociais. ${ }^{7}$

Por outro lado, algumas mulheres puérperas opinam que a atenção da equipe, o tratamento, o atendimento, a alegria, a segurança, o conforto e o cuidado foram positivos para seu bem-estar na situação vivenciada. Estes dados reforçam que ao proporcionar conforto e bem-estar à mulher no trabalho de parto e parto, a equipe de enfermagem auxilia a vivência deste período ao mesmo tempo em que potencializa seu poder vital. ${ }^{8}$

Outros dados desta pesquisa demonstram momentos em que as mulheres puérperas sentiram-se "mais ou menos" bem e apontaram como causas a falta de controle da situação, por ser esta uma situação sem volta, a demora, o castigo da permanência no hospital. Surgiram ainda o medo do processo, o pavor da cesárea inesperada, a solidão e a falta de atenção.

Existe uma tendência na área de saúde que enfatiza a necessidade de se estabelecer um relacionamento terapêutico com o ser humano cuidado. ${ }^{8}$ No caso das mulheres puérperas participantes deste estudo ficou evidente esta necessidade até porque existe uma certa entrega destas ao sistema de saúde, muitas vezes sem a consciência de que estão vivenciando um momento do exercício de sua sexualidade e cidadania feminina.

Quando a mulher submete-se e entrega-se ao sistema de saúde por ocasião do nascimento de um filho, até por estar exposta aos riscos de morte materna, necessita de cuidados singularizados, em que seja vista como um ser humano integral e indivisível. Participativa no seu processo de ter um filho, ela necessita sentir-se, além de respeitada, cuidada e confortada. ${ }^{8}$ A violência contra a mulher, a coerção aos seus direitos de cidadã, e o desrespeito ao exercício de sua sexualidade, precisam deixar de ser encarados como um quadro normal em todas as esferas de ações de saúde, inclusive nas maternidades.

Almejamos que os resultados desta pesquisa, aqui apresentados, venham a contribuir na reflexão sobre a importância do incentivo ou desencorajamento do uso de determinadas técnicas e tecnologias; na incorporação de novas condutas para um cuidado mais adequado e seguro, ajudando na prevenção de distócias e complicações bem como prevenindo a morte materna. Desejamos também 
desencadear reflexões acerca desse momento como o exercício da sexualidade e da cidadania feminina, a fim de influenciar na formação e/ou atualização de profissionais voltados para o cuidado e conforto à mulher, contribuindo para que estes estejam alertas e possuam competência para cuidar e confortar.

Esperamos ainda que a Enfermagem - ciência e arte do cuidar - por estar constantemente próxima da mulher no período de parturição, cuide e conforte-a, para que ela viva este momento de forma saudável e condizente com sua magnitude.

\section{REFERÊNCIA}

1 Carraro TE. Editorial. Texto Contexto Enferm. 2005 Abr-Jun; 14 (2): 153-4.

2 Robertson A. The pain of labour: a feminist issue. Birth Internat. 2001 Jan; 1 [cited 2007 Apr 10]. Available from: http://www.acegraphics.com.au/ resource/papers/painlabour.html

3 Caron OAF, Silva IA. Parturiente e equipe obstétrica: a difícil arte da comunicação. Rev. Latino-American. Enferm. [online] 2002 Jul-Aug; 10 (4): 485-92 [cited 2004 Oct 18]. Avaliable from: http://www.scielo. br/pdf/rlae/v10n4/13359.pdf

4 Radünz V. Cuidando e se cuidando: fortalecendo o self do cliente oncológico e o self da enfermeira. Goiânia (GO): AB; 1999.

5 Coelho MJ, Neves EP, Santos RS, Pereira A, Pereira $\mathrm{M}$, Figueiredo NMA. Conforto e suas interfaces com o cuidar e os cuidados de enfermagem. Rev. Enferm. Atual. 2005 Jul-Ago; 5 (28): 7-13.

6 Morgan BM, Bulpitt CJ, Clifton P, Lewis P. Analgesia and satisfaction in childbirth (The Queen Charlotte's 1000 mother survey). Lancet. 1982 Oct; 9: 808-10.

7 Grüdtner DI. Violência Intrafamiliar contra a criança e o adolescente: reflexões sobre o cuidado de enfermeiras [tese]. Florianópolis (SC):UFSC/PEN; 2005.

8 Carraro TE. Mortes maternas por infecções puerperais: os componentes da assistência de enfermagem no processo de prevenção à luz de Nightingale e Semmelweis [tese]. Florianópolis (SC): UFSC/PEN; 1998.

9 Ministério da Saúde (BR). Parto, aborto e puerpério: assistência humanizada à mulher. Brasília (DF): O Ministério; 2001.

10 Hodnett ED, Gates S, Hofmeyr G J, Sakala C. Continuous support for women during childbirth [Cochrane Review]. Cochrane Library. 2006; 4. Oxford (UK): Update Software; 2006 [cited 2007 Ago 27]. Avaliable from: http://cochrane.bvsalud. org $/$ cochrane $/$ main.php?lang $=$ pt\&lib $=$ COC

11 Knobel R, Radünz V, Carraro TE. Utilização de estimulação elétrica transcutânea para alívio da dor no trabalho de parto: um modo possível para o cuidado à parturiente. Texto Contexto Enferm. 2005 Abr-Jun; 14 (2): 153-4.

12 Bardin L. Análise de conteúdo. Lisboa (PT):Ed. 70; 1977.

13 Knobel R, Carraro TE, Frello AT, Martins MS. Ouvir a parturiente: uma tarefa (im)possível? [CD-ROM]. Florianópolis (SC): RBY Informática Ltda-ME; 2006. 